\title{
Efficacy of GnRH Administration Subsequent to Earliest Recognition of Dominance of Preovulatory Follicle on Fertility in Cows with Prolonged Oestrus
}

\author{
E. Niyas, C. Jayakumar, R. S. Abhilash and S. Reshma* \\ Department of ARGO, College of Veterinary and Animal Sciences, \\ Mannuthy, Thrissur, Kerala, India \\ *Corresponding author
}

\section{A B S T R A C T}

\section{Keywords}

Bovine, Prolonged oestrus, GnRH, Dominant follicle, Ultrasonography

\section{Article Info}

Accepted:

10 January 2021

Available Online:

10 February 2021
Improvement of conception following GnRH treatment during oestrus has been attributed to the prevention of ovulation failure or to reduced variation in the interval to ovulation. The objective of the present study was to assess the efficacy of GnRH administration subsequent to earliest recognition of dominance of preovulatory follicle in repeat breeder (RB) crossbred (CB) cows with prolonged oestrus. All the selected animals $(n=20)$ were observed for oestrous signs twice a day in the morning and evening. Cows in Group I $(n=10)$ were treated with 20 microgram of $\mathrm{GnRH}$ analogue (Buserelin acetate) intramuscularly, when the diameter of preovulatory follicle reached the persistent dominant follicular (DF) size. All the animals were inseminated with frozen-thawed semen $8 \mathrm{~h}$ after administration of GnRH. In group I animals, ovulation occurred within $30 \mathrm{~h}$ of $\mathrm{GnRH}$ administration.Cows in Group II $(\mathrm{n}=10)$ were inseminated with frozen-thawed semen, when the diameter of preovulatory follicle reached the persistent DF size. Further re-inseminations were carried out at $24 \mathrm{~h}$ interval till ovulation was confirmed by transrectal ultrasonography (TRUS). The average number of inseminations in group II animals were 2.60.Pregnancy diagnosis was performed by TRUS on day 28 and confirmation was done on day 60 post AI in both the groups. The conception rates in GnRH treated animals were 60 and 20 per cent respectively in group I and II. The present study concluded that administration of GnRH at the time of persistence of preovulatory follicle at its dominant size improves the conception rate in RB cows with prolonged oestrus.

\section{Introduction}

Dairy sector is a vital part of Indian agriculture. Output generated to Indian economy from livestock included 4 per cent of the GDP and 26per cent of the agricultural GDP.As per the survey by Kerala state poverty eradication mission, five lakh families exclusively depend on livestock sector for their livelihood and another five lakh families are engaged in livestock activities as a subsidiary means of supporting their livelihood. However, cattle population in Kerala shows a decreasing trend during the past decades. Studies revealed that poor reproductive efficiency is the major limiting 
factor that adversely affecting the productivity and profitability of dairying, which makes the dairy industry a less attractive side. The data from Economic review, 2014 clarifies the alarming level of infertility/sub fertility among crossbred cattle of Kerala, the number of inseminations per calving is 3.61 as against the optimum of $1.5-1.7$ (Roberts, 1986). Velayudhakumar (2003) reported an incidence of 29.5 and 35 per cent repeat breeding among crossbred heifers and cows respectively in Kerala. Singh et al., (2009) observed an incidence of $30-40$ per cent prolonged oestrus among repeat breeding crossbred cattle and among crossbred cattle in Kerala, Dhas (2005) noted an incidence of 21.62 and 26.6 per cent prolonged oestrus under farm and field conditions.

Till now numerous works were conducted to reduce the impact of prolonged oestrus on livestock sector. Though treatment protocols derived from these studies helped to find a solution to some extent, a revolutionary change in bovine reproduction field happened only after the introduction of ultrasonography in 1990's.

\section{Materials and Methods}

The study was performed at University Livestock Farm and Fodder Research and Development Scheme (ULF \&FRDS), Mannuthy. Data regarding occurrence of RB with prolonged oestrus in all breedable $\mathrm{CB}$ cattle were collected from breeding registers maintained at ULF \& FRDS, Mannuthy. All the animals with oestrous period longer than $36 \mathrm{~h}$ were considered as cows with prolonged oestrus (Dadarwal et al., 2005). Twenty apparently healthy postpartum crossbred dairy cows with a history of RB with prolonged oestrus, maintained under identical conditions of feeding and management and with a body condition score of 3 or more were selected for the study. Detailed clinico-gynaecological examination was carried out in all selected animals to rule out any anatomical and pathological conditions. Endometritis was ruled out by performing white side test.

The study was carried out in two phases.

In Phase I, the periovulatory follicular dynamics in one oestrus in all the animals $(n=20)$ were studied by TRUS evaluation starting on the day of oestrus and further at 12 $\mathrm{h}$ interval till ovulation. The interval from onset of oestrous signs to maximum follicular diameter, period of follicular dominance and interval from follicular dominance to ovulation were recorded.

In phase II the Cows in the control group (Group II) were inseminated in the subsequent oestrus with frozen semen when the preovulatory follicle reached maximum size of the ovulatory follicle of previous cycle as assessed by TRUS $12 \mathrm{~h}$ apart from the onset of oestrus. Re-insemination at $24 \mathrm{~h}$ interval was carried out in these cows till ovulation was confirmed by TRUS. Number of insemination done in each animal in the control group were recorded. Treatment animals (Group I) were treated with 20 microgram of Buserelin acetate $(\mathrm{GnRH}$ analogue) through intramuscular route when the diameter of preovulatory follicle reached the persistent dominant follicular size. Persistence of the dominant follicle was deemed based on observation of same follicular diameter at two consecutive ultrasonographic observations $12 \mathrm{~h}$ apart. These animals were inseminated with frozen semen $8 \mathrm{~h}$ after $\mathrm{GnRH}$ administration.

The period of follicular dominance and the interval to ovulation following $\mathrm{GnRH}$ administration was documented. Pregnancy was diagnosed by trans-rectal ultrasonography on day 28 after insemination and reconfirmation was done on $60^{\text {th }}$ day of 
gestation to recognize any incidence of pregnancy loss.

\section{Results and Discussion}

In the present investigation TRUS was performed to study the periovulatory follicular dynamics in repeat breeder cows with prolonged oestrus. The efficacy of $\mathrm{GnRH}$ administration subsequent to earliest recognition of dominant follicle on ovulation and fertility in RB cows with prolonged oestrus was also determined.

Interval from onset of oestrus to dominance of ovulatory follicle

Time taken by the pre ovulatory follicle to reach its maximum diameter were between 12 to $24 \mathrm{~h}$ from the onset of oestrus in 50 per cent (10/20) of the animals, 24 to $36 \mathrm{~h}$ in 30 per cent $(6 / 20)$ of the animals and it was between 36 to $48 \mathrm{~h}$ in 20 per cent (4/20) of the animals.

\section{Duration of dominance of preovulatory follicle}

Majority of the animals exhibited a higher duration of persistence of preovulatory follicle size ( $>24 \mathrm{~h}$ in 70 per cent animals). The duration of persistence was between 0 to $12 \mathrm{~h}$ in 20 per cent $(4 / 20), 12$ to $24 \mathrm{~h}$ in 10 per cent $(2 / 20), 24$ to $36 \mathrm{~h}$ in 40 per cent $(8 / 20)$ and 36 to $48 \mathrm{~h}$ in 30 per cent $(6 / 20)$ animals respectively.

These findings are in accordance with Sirois and Fortune (1990) who declared that higher progesterone concentrations at oestrus might lead to prolonged maintenance of ovulatory follicle and hence extended duration of oestrus. They observed that this hormonal asynchrony is due to reduced regression rate of corpus luteum of previous cycle.

\section{Interval from onset of oestrus to ovulation}

Time interval from onset of oestrus to ovulation in the selected animals was between 48 to $60 \mathrm{~h}$ in 60 per cent of the animals $(n=12), 60$ to $72 \mathrm{~h}$ in 10 per cent of the animals ( $n=2), 72$ to $84 \mathrm{~h}$ in 30 per cent of the animals $(n=6)$. No RB animals with prolonged oestrus were ovulated within $48 \mathrm{~h}$ from onset of oestrous signs. The interval from the commencement of oestrus to ovulation in both the group was greater than $48 \mathrm{~h}$ in 100 per cent animals $(n=20)$. These findings are in harmony with the study of Walker et al., (1996) who observed that the RB animals occasionally had longer interval from oestrus to ovulation ( $96 \mathrm{~h}$ ) which was far beyond the normal duration of approximately $27 \mathrm{~h}$ in normally cycling animals. Prolonged persistence of dominant follicle due to an underlying hormonal asynchrony could be the reason for extended duration of oestrus in $\mathrm{RB}$ animals.

Prolonged duration of oestrus in RB animals can be explained with the findings of Bage et al., (2000) who opined that constant adrenal stimulation related with Managemental, environmental and physical stress leads to suprabasal progesterone concentration during oestrus. This increased suprabasal progesterone concentration is adequate to block the positive feedback effect of estradiol on $\mathrm{GnRH}$ release, resulting in delayed $\mathrm{LH}$ peak and ovulation. All these could not be related to the increased number (Average 2.6) of AI done in the control group animals with prolonged oestrus.

\section{Interval from GnRH administration to ovulation}

Treatment animals (Group I) were treated with 20 microgram of Buserelin acetate (GnRH analogue) through intramuscular route when the diameter of preovulatory follicle 
reached the persistent dominant follicular size. These animals were inseminated with frozen semen $8 \mathrm{~h}$ after $\mathrm{GnRH}$ administration.

In all the animals ovulation occurred within $30 \mathrm{~h}$ of $\mathrm{GnRH}$ administration. Kaim et al., (2003) also reported similar finding and stated that use of GnRH during oestrus increases the spontaneous LH peak, prevents delays in ovulation, and induces uniformly high postovulation progesterone concentrations.

\section{Conception rate}

Pregnancy diagnosis by TRUS was performed on day 28post AI in all the three groups and confirmation was done on day 60 post AI. A higher conception rate of 60 per cent was observed in RB animals with prolonged oestrus in group I (Inseminated after $\mathrm{GnRH}$ treatment) as against 20 per cent in RB animals with prolonged oestrus in group II (Inseminated without GnRH treatment). Lucy and Stevenson (1986) reported that administration of $\mathrm{GnRH}$ in periestrous period either prior to or during the LH surge resulted in increased progesterone concentrations in serum the luteal phase of that oestrous cycle. Peters (2005) reported similar findings, administration $\mathrm{GnRH}$ injection at the time of oestrus prevented the ovulation failure or decreased the period from beginning of oestrus to ovulation, thereby increased the conception rate. Ghuman (2014) stated that a synchronized release of endogenous and hormone mediated LH surge of higher amplitude occurs following $\mathrm{GnRH}$ administration at the beginning of oestrus. He also opined a better response following this synchronized release compared to two LH surges of low amplitude following a delayed GnRH administration late in the oestrus.

The present study concluded that administration of $\mathrm{GnRH}$ at the time of persistence of preovulatory follicle at its dominant size improves the conception rate in cows with prolonged oestrus

\section{Acknowledgement}

The authors are thankful to The Professor \& Head, Department of Animal Reproduction, Gynaecology and Obstetrics, The Professor \& Head, University Livestock Farm \& Fodder Research Development Scheme and The Dean, College of veterinary and animal sciences, Mannuthy, Kerala for allowing the facilities of the institution for conducting this research work.

\section{References}

Bage, R., Forsberg, M., Gustafsson, H., Larsson, B. and Rodriguez-Martinez, $\mathrm{H}$. 2000. Effect of ACTH-challenge on progesterone and cortisol levels in ovariectomised repeat breeder heifers. Anim. Reprod. Sci. 63: 65-76.

Dadarwal, D., Singh, J., Honparkhe, M., Cheede, G.S. and Kang R.S. 2005. Investigations on repeat breeding crossbred cattle with history of prolonged estrus. Indian J. Anim. Sci. 75: 922-924.

Dhas, G.J.S. 2005. Fertility trials on induced oestrum in repeat breeding cattle with prolonged oestrum. M.V.Sc thesis, Kerala Agricultural University, Thrissur, 39p.

Ghuman, S.P.S., Honparkhe, M., Dadarwal, J.S. and Dhaliwal, G. 2014. Optimizing estrous period characteristics of crossbred cows exhibiting prolonged estrus using a PGF $2 \alpha$ analogue. Indian J. Anim. Sci. 84: 15-17.

Kaim, M., Bloch, A., Wolfenson, D., BrawTal, R.O.S.E.M.B.E.R.G., Rosenberg, M., Voet, H. and Folman, Y., 2003. Effects of GnRH administered to cows at the onset of estrus on timing of ovulation, endocrine responses, and 
conception. Journal of dairy science, 86(6), pp.2012-2021.

Lucy, M.C. and Stevenson, J.S., 1986. Gonadotropin-releasing hormone at estrus: luteinizing hormone, estradiol, and progesterone during the periestrual and postinsemination periods in dairy cattle. Biology of Reproduction, 35(2), pp.300-311.

Peters, A.R., 2005. Veterinary clinical application of $\mathrm{GnRH}$ - questions of efficacy. Animal reproduction science, 88(1-2), pp.155-167.

Roberts, S.J. (1986). Veterinary obstetrics and genital diseases (Theriogenology). (3rdEdn). Woodstock publishing, Vermont.

Singh, J., Dadarwal, D., Honparkhe, M., Kumar, A., Cheede, G.S. and Kang, K.S. 2009. Factors responsible for repeat breeding syndrome in cattle and buffaloes of Malwa region of Punjab. Internet. J. Vet. Med., 6(1): Available: http: www.ispub.com/journal/33_5/en/3.pdf. ISSN 28[13 Feb. 2015].

Sirois, J. and Fortune, J.E. 1990. Lengthening of the bovine estrous cycle with low levels of exogenous progesterone: a model for studying ovarian follicular dominance. Endocrinology. 127: 916925.

Velayudakumar, R. 2003. Effect of human chorionic gonadotrophin, Gonadotrophin releasing hormone and prostaglandin $\mathrm{F}_{2 \alpha}$ in augmenting conception rate of repeat breeder cattle. M.V.Sc. thesis, Kerala Agricultural University Trichur, $85 \mathrm{p}$.

Walker, W.L., Nebel, R.L. and McGilliard, M.L., 1996. Time of ovulation relative to mounting activity in dairy cattle. Journal of dairy science, 79(9), pp. $1555-1561$.

\section{How to cite this article:}

Niyas, E., C. Jayakumar, R. S. Abhilash and Reshma, S. 2021. Efficacy of GnRH Administration Subsequent to Earliest Recognition of Dominance of Preovulatory Follicle on Fertility in Cows with Prolonged Oestrus. Int.J.Curr.Microbiol.App.Sci. 10(02): 1356-1360. doi: https://doi.org/10.20546/ijcmas.2021.1002.161 